\title{
Differential cell count as an alternative method to diagnose dairy cow mastitis
}

\author{
R. Pilla, ${ }^{*}$ M. Malvisi, ${ }^{*}$ G. G. M. Snel, ${ }^{*}$ D. Schwarz,† S. König,‡ C.-P. Czerny,† and R. Piccinini ${ }^{* 1}$ \\ *Department of Veterinary Sciences and Public Health, University of Milan, Via Celoria 10, 20133 Milan, Italy \\ †Department of Animal Sciences, Institute of Veterinary Medicine, Division of Microbiology and Animal Hygiene, Faculty of Agricultural Sciences, \\ Georg-August-University Göttingen, Burckhardtweg 2, D-37077 Göttingen, Germany \\ ‡Department of Animal Breeding, University of Kassel, Nordbahnhofstraße 1a, D-37213 Witzenhausen, Germany
}

\begin{abstract}
Changes in relative cell proportions occurring in diseased mammary glands of dairy cows can be determined using differential cell count (DCC). The present study was carried out in 2 consecutive trials, with 2 goals: (a) to test the consistency of DCC results on subsequent days, and (b) to establish an effective cutoff value for the diagnosis of mastitis. In the first trial, quarter milk and blood samples were taken from 8 healthy cows for 5 consecutive days. Milk samples were tested by somatic cell count (SCC) and bacteriological analysis, and DCC was performed on blood and milk samples by flow cytometer. In the second trial, 16 animals were randomly selected from a different herd and quarter milk samples taken on 3 consecutive milkings. All samples were cyto-bacteriologically analyzed and DCC was performed on the second sampling. In the first trial, mean SCC was 77,770 cells $/ \mathrm{mL}$ and 4 samples were bacteriologically positive. No fixed or random effect had a significant influence on percentages of individual cell populations or ratios in blood or milk. A cutoff value of 0.495 for logarithmic polymorphonuclear neutrophilic leukocyte:lymphocyte ratio was established. Mean SCC of milk samples collected in the second trial was 543,230 cells $/ \mathrm{mL}$, and infection was detected in $53.1 \%$ of quarters, mostly caused by Staphylococcus aureus. When the cutoff value was applied to the data along with SCC, sensitivity and specificity of the diagnostic method were 97.3 and $92.3 \%$, respectively.
\end{abstract}

Key words: dairy cow, differential cell count, diagnosis, subclinical mastitis

\section{INTRODUCTION}

Subclinical mastitis is a major health problem in dairy cattle. Economic losses are mostly associated with decreased production and milk quality. Such infections are not evident and can persist in the mammary

Received October 22, 2012.

Accepted November 22, 2012.

${ }^{1}$ Corresponding author: renata.piccinini@unimi.it tissue throughout lactation. Staphylococcus aureus is a contagious pathogen and a major agent of subclinical mastitis (IDF, 2006), but the infection can also be caused by a wide range of environmental and opportunistic pathogens (Bradley, 2002).

Subclinical mastitis can be diagnosed by SCC, bacteriological analysis, or PCR. The International Dairy Federation recommends the use of both SCC and bacteriological analysis for the determination of udder health (Hogan et al., 1999). Accordingly, the diagnosis of bovine mastitis is mostly based on cyto-bacteriological analysis of milk samples (Vangroenweghe et al., 2002). Despite that, identification of infected quarters presents difficulties related to the possibility of falsenegative bacteriological results and infections without a concomitant increase of SCC (Schwarz et al., 2010).

Differential cell count (DCC) shows changes in relative cell proportions, which can be used to differentiate healthy glands from inflamed or infected glands, and DCC has been proposed as a valid tool for the identification of inflammatory processes in cases with low SCC (Rivas et al., 2001). Recent studies (Schwarz et al., 2011a,b; Pilla et al., 2012) have shown that DCC can reveal inflammatory processes, even in milk with SCC of 1,000 cells $/ \mathrm{mL}$, well below the current threshold of 100,000 cells/mL (DVG, 2002).

Differential cell count can be performed using different methods. Microscopic DCC is a simple and cost-effective method, but most researchers prefer cytometric analysis because of its higher accuracy. Leitner et al. (2000b) found a high correlation between the 2 methods for PMNL and lymphocytes, but a lower correlation for macrophages and epithelial cells, probably because of the difficulty in differentiating between these cell populations with light microscopy. Different cell patterns have been documented during the course of infection in the presence of different pathogens (Leitner et al., $2000 \mathrm{~b})$. In acute mastitis, PMNL are the predominant cell type, often accounting for more than $90 \%$ of the total mammary leukocyte population (Sordillo and Streicher, 2002). In contrast, in chronic mastitis caused by Staph. aureus and CNS, PMNL percentages can vary from the high values seen in acute mastitis to per- 
centages as low as those recorded in uninfected quarters (Leitner et al., 2000b, 2003; Riollet et al., 2001). The effect of lactation stage and parity number should also be taken into account. Lymphocytes and monocytes are reported to be higher in early lactation than in mid and late lactation, whereas macrophages and PMNL percentages are considerably lower (Dosogne et al., 2003).

Lymphocytes, macrophages, and PMNL play an important role in the immunity of the mammary gland (Paape et al., 1979; Sordillo and Nickerson, 1988). A successful defense against invading pathogens depends on number and distribution of leukocytes (Leitner et al., 2003). In healthy milk, the percentage of each cell type is widely variable; according to some researchers, macrophages are the predominant cell type (Riollet et al., 2001; Lindmark-Mansson et al., 2006), whereas others have shown that lymphocytes are the major population (Park et al., 1992; Leitner et al., 2000a; Schwarz et al., 2011a,b). Leitner et al. (2000a) demonstrated a high repeatability for samples taken from the same cow in different stages of lactation and suggested that the leukocyte pattern in uninfected mammary glands is genetically controlled. To the best of our knowledge, however, no information on short-term repeatability is available. Because the immune system is dynamic and the mammary gland is subjected to persistent stress during lactation, a basic knowledge of the cellular profile in healthy glands is fundamental. Therefore, the goals of the present study were (a) to investigate DCC in milk from healthy mammary quarters and to test whether the results are consistent on subsequent days; and b) to establish an effective cutoff value for the diagnosis of mastitis that is applicable under field conditions. The study was carried out in 2 consecutive trials, the first to determine DCC stability and cutoff and the second to test this cutoff value under field conditions.

\section{MATERIALS AND METHODS}

\section{Animals and Milk Sampling}

Trial 1. To investigate DCC in healthy quarters and its test-retest reliability, the herd enrolled in the first trial was located in the Lombardy region of Italy, and was certified free of paratuberculosis, bovine viral diarrhea, and infectious bovine rhinotracheitis; it also had no history of contagious mastitis pathogens in the last $10 \mathrm{yr}$. The herd consisted of 50 lactating HolsteinFriesian dairy cows housed in freestalls and milked twice daily in a milking parlor.

Eight cows were selected based on low SCC and 2 negative results of bacteriological analysis in the week before samplings. Of these, 3 cows were primiparous, 4 were in the second or third lactation, and 1 had calved 4 times. Two animals were in early lactation (83 to 111
DIM), 3 were in mid lactation (144 to 172 DIM), and 3 in late lactation (233 to 357 DIM).

Blood and quarter milk were sampled on 5 consecutive days at morning milking. All cows were free of clinical signs of mastitis at sampling. After cleaning and disinfection of the teat, the first squirts of milk were discarded, and $250 \mathrm{~mL}$ of milk was aseptically collected from each quarter into sterile plastic tubes (Falcon, BD Biosciences, Franklin Lakes, NJ) for both bacteriological and DCC analysis. Blood samples (10 $\mathrm{mL}$ ) were collected by tail venipuncture into commercial EDTA-containing evacuated tubes (Vacutainer, BD Biosciences, San Jose, CA). Samples were refrigerated until arrival at laboratory facilities.

Trial 2. The calculated cutoff value was tested under field conditions in another herd located in Lombardy that was participating in a voluntary control program for contagious mastitis. The herd consisted of 180 lactating Holstein-Friesian dairy cows housed in freestalls and milked twice daily in a milking parlor. The herd had a history of high prevalence of Staph. aureus (approximately $50 \%$ prevalence at the beginning of the control program), and mammary infections caused by Prototheca zopfii had recently been detected.

In total, 16 cows were randomly selected from the last milking group, which included animals previously diagnosed as infected with Staph. aureus or P. zopfii and other animals before culling. Of these, 9 cows were primiparous and 7 multiparous.

Quarter milk samples for bacteriological analysis were collected at 3 consecutive milkings. After cleaning and disinfection of the teat, the first 2 squirts of milk were discarded, and $10 \mathrm{~mL}$ of foremilk was aseptically collected in sterile plastic tubes (Bioster, Seriate, Italy). At the second milking, an additional $200 \mathrm{~mL}$ of quarter milk was sampled for DCC analysis. Samples were refrigerated until arrival at laboratory facilities.

\section{SCC and Bacteriological Analysis}

All samples were submitted to bacteriological analysis, which was performed as previously described (Oliver et al., 2004). Briefly, an aliquot of $10 \mu \mathrm{L}$ of each sample was spread onto blood agar plates ( $5 \%$ bovine blood, Oxoid, Basingstoke, UK) and plates were incubated at $37^{\circ} \mathrm{C}$. Plates were evaluated after 24 and 48 $\mathrm{h}$, and colonies of growth were isolated. All colonies were identified by biochemical tests following Hogan et al. (1999). Somatic cells were counted on a Bentley Somacount 150 (Bentley Instruments, Chaska, MN).

\section{DCC}

Differential cell counts were performed on blood samples and quarter milk samples by cytometry. Milk cells 
were isolated according to the protocol described by Koess and Hamann (2008), with modified centrifugation conditions. Briefly, $200 \mathrm{~mL}$ of milk was centrifuged at $250 \times g$ for $30 \mathrm{~min}$ at $4^{\circ} \mathrm{C}$. The cream layer and supernatant were discarded and the cell pellet was washed twice in $30 \mathrm{~mL}$ of PBS. Blood erythrocytes were lysed with Cell Lysis solution (A7933, Promega, Madison, WI) and leukocytes were collected by centrifugation at $500 \times g$ for $10 \mathrm{~min}$ at room temperature.

Cell pellets were resuspended in $500 \mu \mathrm{L}$ of RPMI 1640 with $10 \%$ fetal calf serum, and cells were counted in a hemocytometer; finally, the cell concentration was adjusted to $2 \times 10^{6}$ cells $/ \mathrm{mL}$. Aliquots of $100 \mu \mathrm{L}$ of each sample were incubated with antibodies conjugated to fluorescein isothiocyanate (FITC) or R-phycoerythrin (RPE; Table 1) for $30 \mathrm{~min}$ at $4^{\circ} \mathrm{C}$. Cells were then washed in PBS once and resuspended in PBS with $2 \%$ formalin. Fixed cells were kept at $4^{\circ} \mathrm{C}$ for 3 to $18 \mathrm{~h}$ and analyzed using a FACScalibur flow cytometer and Cell Quest software (Becton Dickinson, San Jose, CA). Eight thousand events were acquired per sample, and data were further analyzed using Cyflogic v. 1.2.1 free software (CyFlo Ltd., Turku, Finland).

Percentages of PMNL, lymphocytes, and macrophages were calculated. In addition, to increase the discrimination power of DCC, the ratios logarithmic PMNL:lymphocytes (log PMNL:Lym) and logarithmic phagocytes:lymphocytes (log Phag:Lym) were calculated as previously described (Pilla et al., 2012).

\section{Statistical Analysis}

Trial 1. Linear mixed models were applied on the data from the first trial to analyze the impact of fixed effects, random effects, and covariates on DCC in milk and blood. The statistical model was defined as follows:

$$
\begin{aligned}
\mathrm{y}_{\mathrm{ijklm}} & =\mu+\text { parity }_{\mathrm{i}}+\mathrm{DIM}_{\mathrm{j}}+\text { quarter }_{\mathrm{k}}+\text { cow }_{\mathrm{l}} \\
& +\alpha_{1} \text { day }+ \text { DIM } \times \alpha_{1} \text { day }_{\mathrm{ijkl}}+\mathrm{e}_{\mathrm{ijklm}},
\end{aligned}
$$

where $\mathrm{y}_{\mathrm{ijklm}}=\mathrm{DCC}$ of cow $\mathrm{l}, \mu=$ overall mean effect, parity $_{i}=$ fixed effect of parity i (first parity or higher lactation number), $\mathrm{DIM}_{\mathrm{j}}=$ fixed effect for classes of
DIM $\mathrm{j}$ (early, mid, or late), quarter = fixed effect of udder quarter $\mathrm{k}$, cow $=$ random effect of cow 1 , day $=$ consecutive number of measurements within cow from d 1 to 5 (sampling number), $\alpha_{1}=$ linear regression of sampling number on DCC, DIM $\times \alpha_{1} \mathrm{day}_{\mathrm{ijkl}}=$ interaction between DIM and sampling number, and $\mathrm{e}_{\mathrm{ijk} k \mathrm{~m}}=$ random residual effect belonging to observation $\mathrm{y}_{\mathrm{ijklm}}$.

For blood samples, the effect of udder quarter was excluded from the statistical model. Least squares means for the covariate "day" stratified by DIM were generated by using the "at - statement" for sequenced data as implemented in Proc Mixed of SAS (SAS Institute Inc., Cary, NC).

The cutoff value between healthy and diseased cows for log PMNL:Lym in milk was determined considering quarters samples with $\mathrm{SCC}<10^{5}$ cells $/ \mathrm{mL}$ and negative bacteriological results as healthy, and attributing them a score of 0 . All other samples were considered diseased and attributed a score of 1 . The log PMNL:Lym values and attributed scores were then tested with receiver operator characteristics analysis using SPSS version 17.0 statistical software (SPSS Inc., Chicago, IL), and a cutoff value was chosen to maximize sensitivity and specificity.

Trial 2. Quarter milk samples were classified as diseased or healthy as described in the previous section. Bacteriological analysis and SCC were considered the gold standard test. The cutoff value was then applied to calculated log PMNL:Lym. All quarters with values below the cutoff were considered healthy, and those with values above the cutoff were considered diseased. A score of 0 was attributed to healthy samples and a score of 1 to the others. Sensitivity and specificity of the method were then calculated under field conditions.

\section{RESULTS}

\section{SCC and Bacteriological Analysis}

Trial 1. Mean SCC of the 159 quarter milk samples considered was 77,770 cells/mL (SD 185,510). Thirtyfour samples had SCC $>100,000$ cells $/ \mathrm{mL}$, with a maximum value of $1,512,000$ cells $/ \mathrm{mL}$. Only 4 samples were bacteriologically positive: CNS were detected in

Table 1. Antibodies used for cytometric analysis (all purchased from Ab Serotec, Oxford, UK)

\begin{tabular}{llll}
\hline CD molecule $^{1}$ & Antibody type & Specificity & $\begin{array}{l}\text { Antibody } \\
\text { clone }\end{array}$ \\
\hline CD11b-FITC & Mouse IgG2b & Granulocytes & CC126 \\
CD14-PE & Mouse IgG2a & Monocytes & TÜK4 \\
CD21-PE & Mouse IgG1 & B Lymphocytes & CC21 \\
CD5-FITC & Mouse IgG1 & T Lymphocytes & CC17 \\
\hline
\end{tabular}

${ }^{1}$ FITC $=$ fluorescein isothiocyanate $\mathrm{PE}=$ R-phycoerythrin. 
Table 2. Mean values and standard deviations for individual cell populations and combinations of cell populations in milk

\begin{tabular}{lcc}
\hline $\begin{array}{l}\text { Cell population } \\
\text { or ratio }\end{array}$ & Mean & SD \\
\hline PMNL (\%) & 43.1 & 23.5 \\
Lymphocytes (\%) & 30.1 & 19.4 \\
Macrophages (\%) & 26.9 & 15.7 \\
log PMNL:Lym & 0.22 & 0.62 \\
log Phag:Lym & 0.48 & 0.53 \\
\hline
\end{tabular}

${ }^{1} \log$ PMNL:Lym = logarithmic PMNL:lymphocyte ratio; log Phag:Lym $=$ logarithmic phagocyte:lymphocyte ratio.

3 samples and Streptococcus spp. in 1 sample. Data from positive quarters were excluded from the statistical analysis but included for the cutoff determination.

Trial 2. Mean SCC of the 192 milk samples considered was 543,230 cells/mL (SD 816,730). One hundred and two samples $(53.1 \%)$ were bacteriologically positive: Staph. aureus was isolated from 71 samples, Prototheca sp. were detected in 12 samples, CNS in 11 samples, Enterococcus faecalis in 7, and Serratia sp. in 1 sample. Twenty-seven quarters were considered healthy. Thirty-five quarters were considered diseased based on isolation of Staph. aureus, or at least $10^{3} \mathrm{cfu} / \mathrm{mL}$ of Prototheca in one or more samples, or on the detection of other pathogens in all 3 samples. Two quarters were considered diseased because the mean SCC was $>100,000$ cells $/ \mathrm{mL}$.

\section{DCC}

Trial 1. Overall ( $\mathrm{n}=155$ samples), mean proportion of PMNL was $43.1 \%$ (SD 23.5\%), that of lymphocytes was $30.1 \%$ (SD 19.4\%), and that of macrophages was 26.9\% (SD 15.7\%). The ratios log PMNL:Lym and log Phag:Lym had mean values of 0.22 (SD 0.62) and 0.48 (SD 0.53), respectively (Table 2).

Results of variance analysis of milk data are summarized in Table 3. Sampling day showed no significant effect on percentages of individual cell populations $(P$ - values from 0.68 to 0.99 ). Associating individual cell populations into ratios produced similar results, with $P$-values of 0.89 and 0.81 for log PMNL:Lym and $\log$ Phag:Lym, respectively. Even though some differences related to lactation stage were found for all variables, $P$-values ranged from 0.73 to 0.89 . Finally, neither parity nor quarter position had a significant influence on percentages of cell populations or ratios. Variance analysis of blood data showed similar results (Table 4): sampling day, parity, and lactation stage had no significant effect on the percentages of individual cell populations or ratios.

Figure 1 and 2 show least squares means in milk for individual cell populations or ratios on each sampling day, corrected for quarter position and parity, and separated by lactation stage. Even though no significance could be attributed to lactation stage, a trend to increasing lymphocyte percentages and decreasing macrophage values was seen over the course of lactation (Figure 3). Analogously, older cows were more likely to have higher log PMNL:Lym compared with first- or second-parity cows, but the differences were not significant (Figure 4). The results of blood analysis were similar to those of milk (Figure 5).

The area under the receiver operator characteristic curve used for the cutoff determination was 0.775 . With a cutoff value of 0.495 , sensitivity was $73.3 \%$ and specificity $73.6 \%$.

Trial 2. When the cutoff value determined in trial 1 was applied to the data of the second trial, 28 out of 64 quarters were correctly classified as positive and 24 as negative, whereas 2 quarters were false positives and 9 quarters were false negatives. Calculated sensitivity and specificity under field conditions were 75.7 and $92.3 \%$, respectively.

\section{DISCUSSION}

Differential cell count has been proposed as a valid tool for the identification of inflammatory processes in

Table 3. Probability values for testing significance of fixed effects of quarter position, parity, lactation stage, and the linear regression of sampling day on the percentage of individual cell populations and combinations of cell populations in milk ${ }^{1}$

\begin{tabular}{lcccc}
\hline $\begin{array}{l}\text { Cell population } \\
\text { or ratio }\end{array}$ & $\begin{array}{c}\text { Quarter } \\
\text { position }\end{array}$ & Parity & $\begin{array}{c}\text { Lactation } \\
\text { stage }\end{array}$ & $\begin{array}{c}\text { Sampling } \\
\text { day }\end{array}$ \\
\hline PMNL & 0.53 & 0.90 & 0.76 & 0.78 \\
Lymphocytes & 0.23 & 0.23 & 0.79 & 0.98 \\
Macrophages & 0.63 & 0.24 & 0.89 & 0.68 \\
log PMNL:Lym & 0.56 & 0.57 & 0.73 & 0.89 \\
log Phag:Lym & 0.65 & 0.30 & 0.79 & 0.81 \\
\hline
\end{tabular}

${ }^{1}$ Analyzed factors were quarter position (front right, rear right, front left, and rear left), parity (1 or 2 , and 3 or 4), lactation stage (early, mid, or late lactation), and sampling day (d 1 to 5 ).

${ }^{2} \log$ PMNL:Lym = logarithmic PMNL:lymphocyte ratio; log Phag:Lym = logarithmic phagocyte:lymphocyte ratio. 
Table 4. Probability values for testing significance of fixed effects of parity, lactation stage, and the linear regression of sampling day on the percentage of individual cell populations and combinations of cell populations in blood ${ }^{1}$

\begin{tabular}{lccc}
\hline $\begin{array}{l}\text { Cell population } \\
\text { or ratio }\end{array}$ & Parity & $\begin{array}{c}\text { Lactation } \\
\text { stage }\end{array}$ & $\begin{array}{c}\text { Sampling } \\
\text { day }\end{array}$ \\
\hline PMNL & 0.22 & 0.87 & 0.19 \\
Lymphocytes & 0.13 & 0.65 & 0.13 \\
Macrophages & 0.11 & 0.07 & 0.33 \\
log PMNL:Lym & 0.19 & 0.64 & 0.09 \\
log Phag:Lym & 0.16 & 0.54 & 0.08 \\
\hline
\end{tabular}

${ }^{1}$ Analyzed factors were parity ( 1 or 2 , and 3 or 4 ), lactation stage (early, mid, or late lactation), and sampling day (d 1 to 5).

${ }^{2} \log$ PMNL:Lym = logarithmic PMNL:lymphocyte ratio; log Phag:Lym $=$ logarithmic phagocyte:lymphocyte ratio.

animals with low SCC (Rivas et al., 2001). Recent studies confirmed that DCC can be used to detect inflammatory processes in milk samples with extremely low SCC (Schwarz et al., 2011a,b; Pilla et al., 2012). Given the constant pressure in the lactating mammary gland and the dynamism of the immune system, information on the short-term repeatability of DCC is important to evaluate the applicability of the method as a tool in mastitis control programs.

The aims of the present study were to evaluate whether the results of DCC are consistent on subsequent days, using both individual cell population and the 2 ratios to increase the discrimination power of DCC as previously reported (Pilla et al., 2012). A further aim of the study was to establish a cutoff value for $\log$ PMNL:Lym, the ratio that best identified healthy and diseased quarters (Pilla et al., 2012), and to verify its applicability under field conditions.

Differential cell counts can be obtained by flow cytometry or light microscopy. Leitner et al. (2000b) reported a high correlation between the 2 methods for PMNL and lymphocytes and a lower correlation for macrophages and epithelial cells. Although light microscopy is a cost-effective method, cytometry is more precise, allowing the evaluation of a higher number of cells per sample (Koess and Hamann, 2008). Therefore, cytometric analysis was chosen for DCC testing.

Animals considered in the first trial were selected from a herd free of contagious mastitis pathogens, with high health and hygiene standards. The choice of a commercial herd characterized by excellent management allowed us to reduce the influence of diseases or systemic pathologies unrelated to the mammary gland. To that end, blood samples were taken to verify that eventual fluctuations in milk data could be related to systemic conditions.

Fluctuations in SCC were observed in all but 3 quarters during the follow-up period, but no significant variation in DCC could be recorded. Even though 4
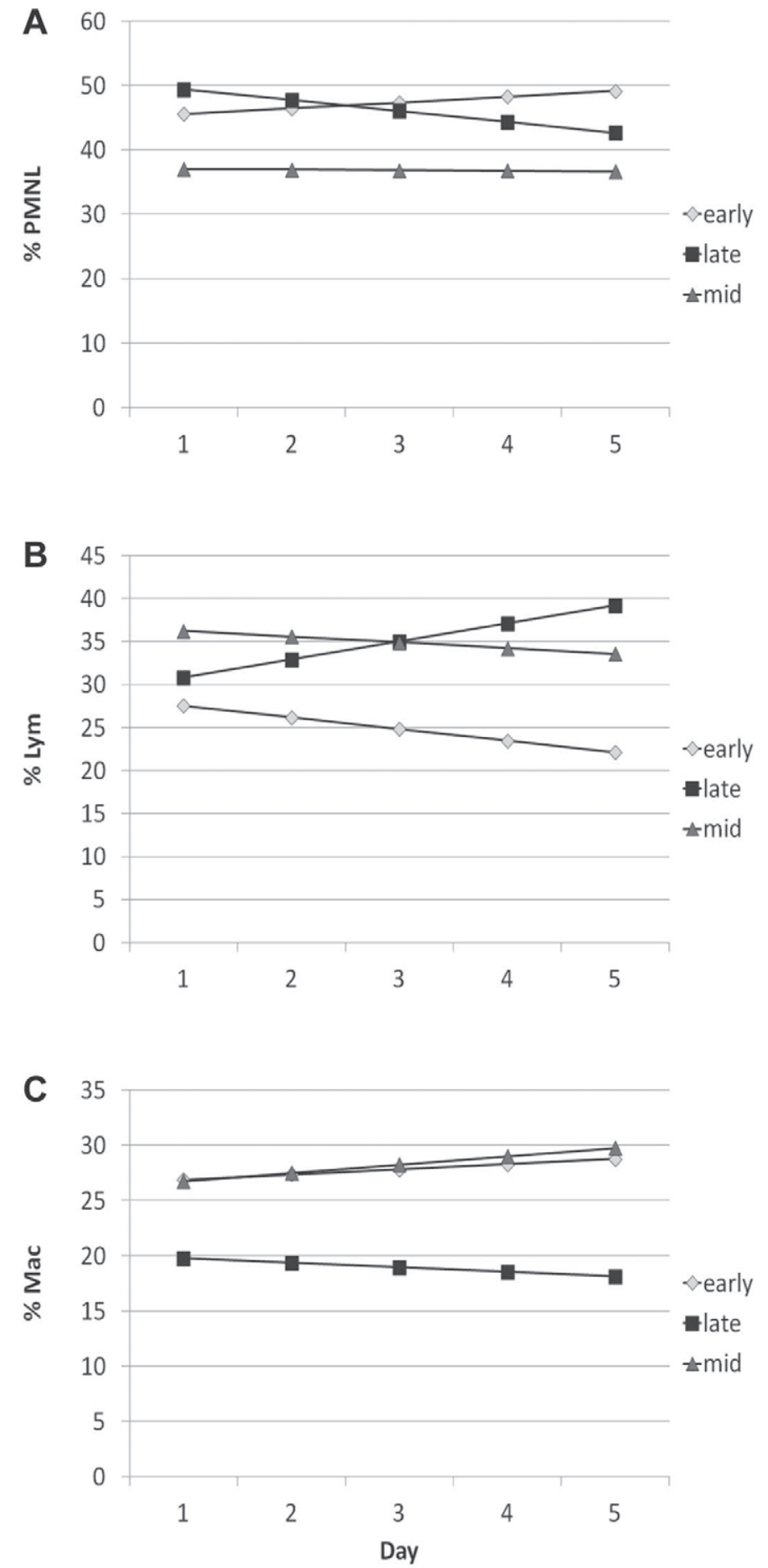

Figure 1. Least squares means of percentages of (A) PMNL, (B) lymphocyte (Lym), and (C) macrophages (Mac) in milk for each sampling day, separated by lactation stage (early, mid, or late).

samples were bacteriologically positive, no bacteria could be detected in the following samples, thus infections were considered transient. Therefore, each positive milk sample was excluded from the analysis, 

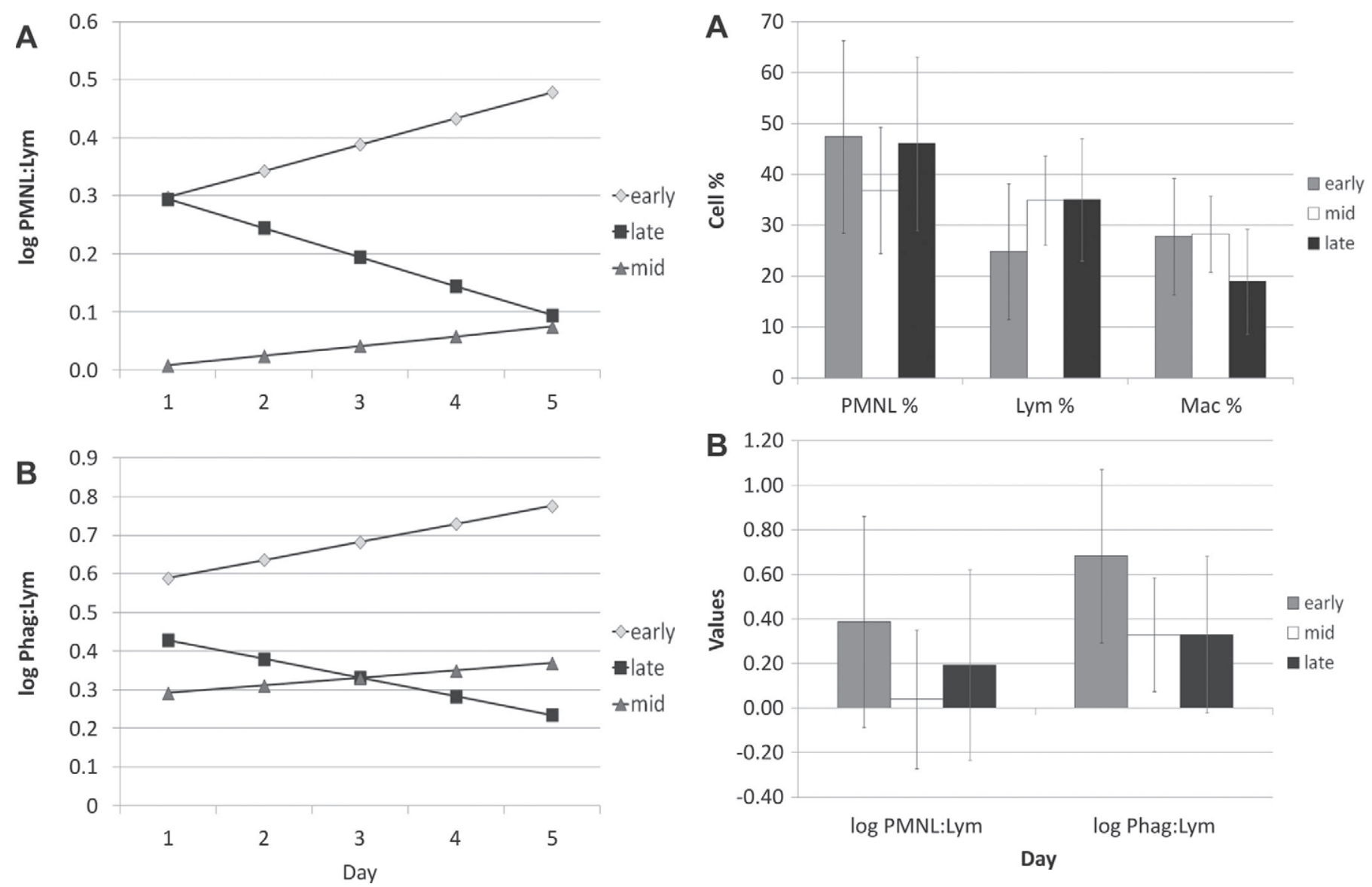

Figure 2. Least squares means of (A) logarithmic PMNL:lymphocyte ratio (log PMNL:Lym), and (B) logarithmic phagocyte:lymphocyte (log Phag:Lym) ratio in milk, for each sampling day, separated by lactation stage (early, mid, or late).

Figure 3. Least squares means and standard error of (A) PMNL, lymphocyte (Lym), and macrophage (Mac) percentages; and (B) logarithmic PMNL:lymphocyte (log PMNL:Lym) and logarithmic phagocyte:lymphocyte (log Phag:Lym) ratios in milk, separated by lactation stage (early, mid, or late).

but the animals were still considered healthy and were not excluded from the experiment. Even though no significant difference could be found among sampling days, variations in DCC could be seen in some quarters but were not correlated with SCC variation (data not shown).

Fluctuations of individual cell populations in milk were observed in different stages of lactation, but the differences were not significant, in agreement with Pilla et al. (2012) but in contrast to Dosogne et al. (2003), who reported higher lymphocytes and lower macrophages at the beginning of lactation.

These results suggest that DCC can be reliably applied in samples collected in different stages of lactation to evaluate the health status of the mammary gland, even though single variations observed in a few samples could indicate the possibility of misclassification.

The results obtained in the second trial using the cutoff value calculated in the first trial showed very

high specificity and good sensitivity. Of the 9 falsenegative quarters, 2 were considered as diseased based on SCC only, 4 were positive for Staph. aureus, 2 for Prototheca spp., and 1 for CNS. If both SCC and DCC were considered, only 1 quarter would be misclassified, increasing the sensitivity of the method to $97.3 \%$, without any changes in specificity. That quarter had very low SCC (1,000 cells/mL in all samplings), and Staph. aureus was detected at low levels in only the first and second samplings $\left(10^{2} \mathrm{cfu} / \mathrm{mL}\right)$. Because the animal had 2 Staph. aureus-infected quarters shedding high numbers of bacteria, we speculated that the bacteriological positivity of the other quarter could reflect a transient contamination of the teat canal that was adequately prevented from reaching the gland cistern by local defense mechanisms. Such teat canal contaminations have been previously reported and do not always correlate with intramammary infections (Zecconi et al., 1994). 

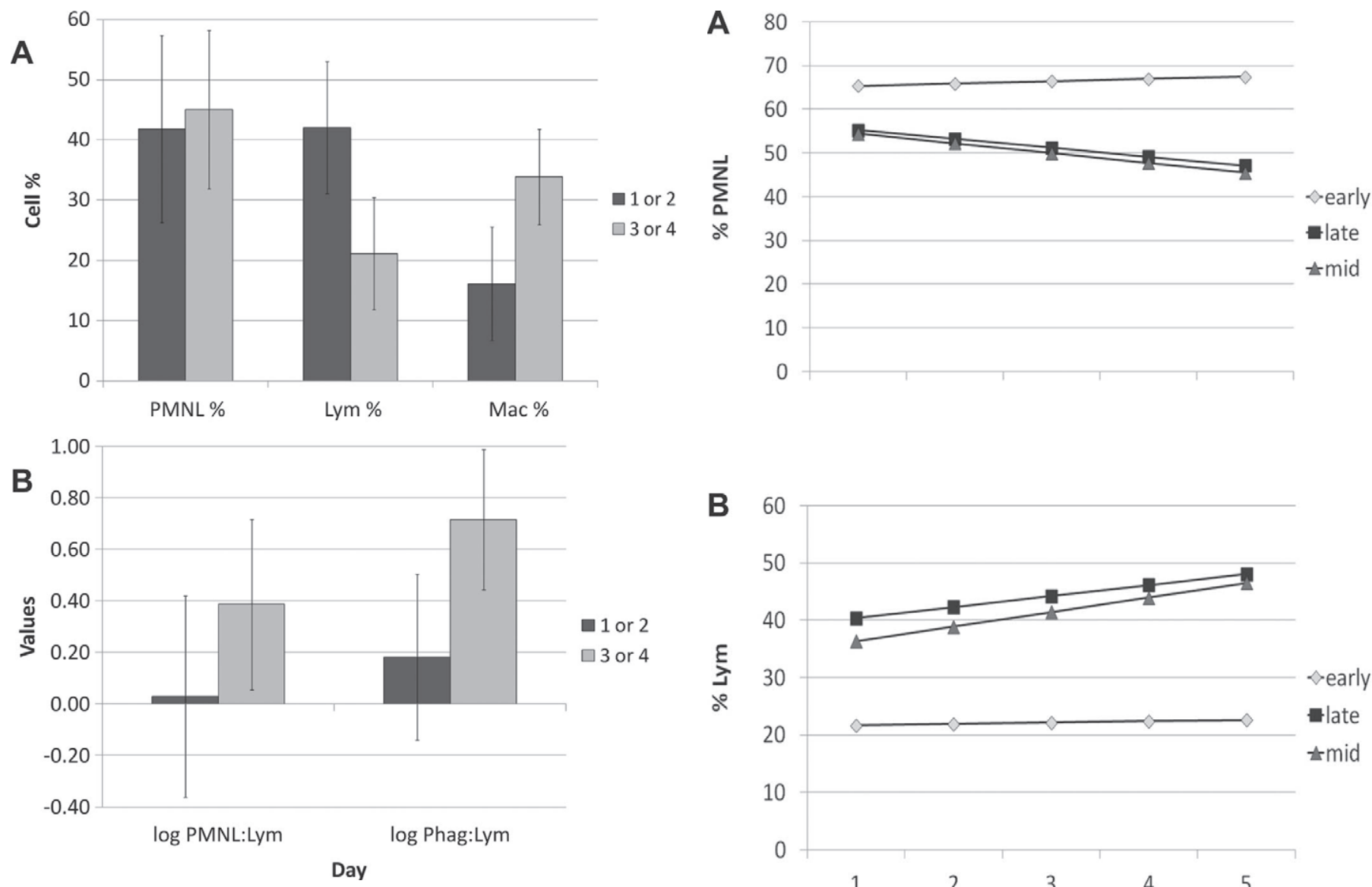

Figure 4. Least squares means and standard error of (A) PMNL, lymphocyte (Lym), and macrophage (Mac) percentages; and (B) logarithmic PMNL:lymphocyte (log PMNL:Lym) and logarithmic phagocyte:lymphocyte (log Phag:Lym) ratios in milk, separated by parity number. Dark gray bars represent animals that calved once or twice, and light gray bars represent animals that calved 3 or 4 times.

\section{CONCLUSIONS}

Differential cell counting can identify inflammatory processes in quarters with low SCC that are otherwise considered healthy. Information on the consistency of this method is important to evaluate the applicability of DCC in mastitis control programs. In the present study, we considered healthy mammary quarters to establish the test-retest reliability of a previously described combined variable used to identify healthy or diseased quarters and to establish a cutoff value to be used in the field. No influence of sampling day, parity, lactation stage, or quarter position could be found on either milk or blood DCC results; therefore, a cutoff value could be established to identify healthy or diseased quarters. A cutoff value of 0.495 , tested under field conditions, confirmed the previous results. Finally, data obtained in the field showed that by combining SCC with the cutoff value of 0.495 for DCC, sensitivity
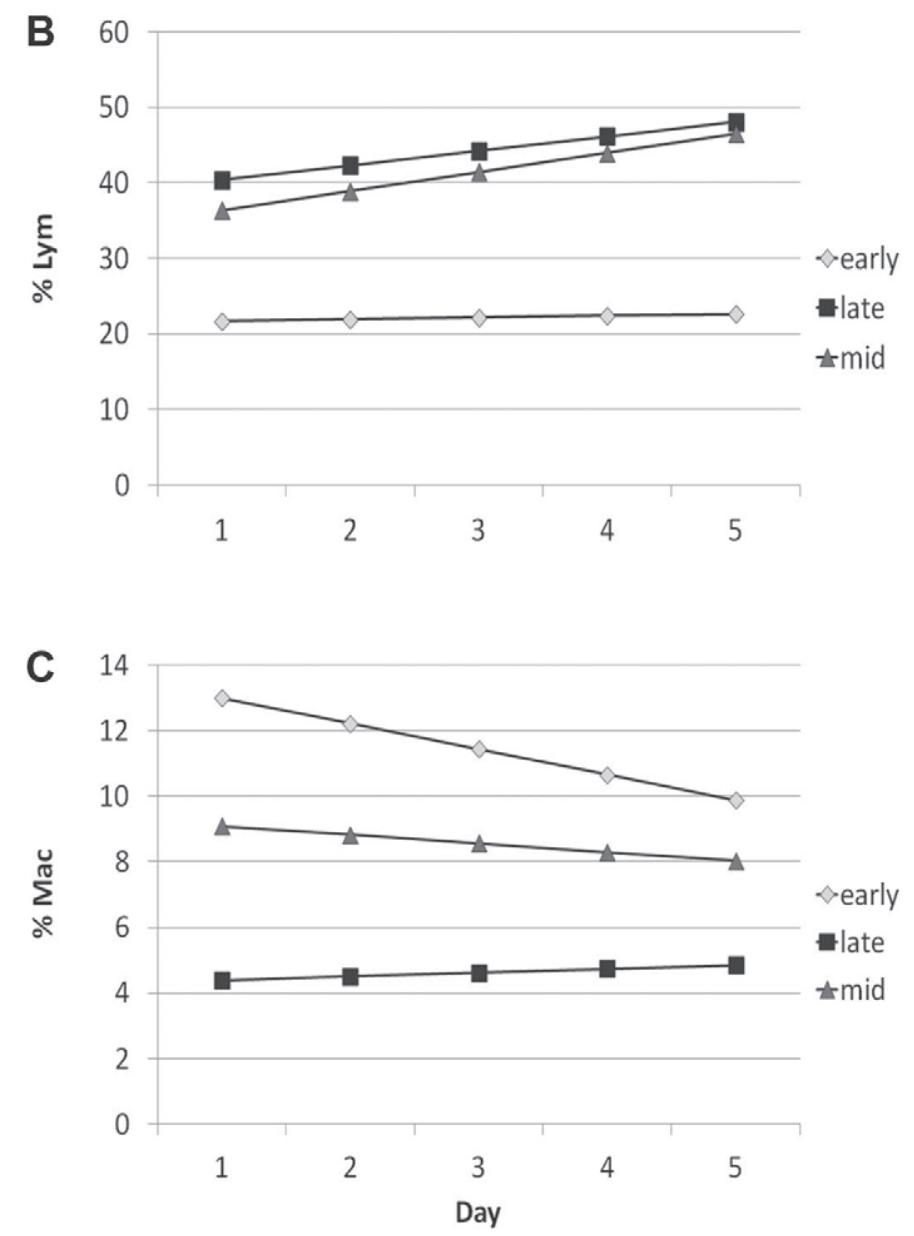

Figure 5. Least squares means of percentages of (A) PMNL, (B) lymphocyte (Lym), and (C) macrophage (Mac) in blood for each sampling day, separated by lactation stage (early, mid, or late).

and specificity increased to 97.3 and $92.3 \%$, respectively. In conclusion, the use of both cytometric DCC and SCC could represent an excellent diagnostic method to identify inflammatory processes in the mammary gland while avoiding bacteriological analysis. 


\section{REFERENCES}

Bradley, A. J. 2002. Bovine mastitis: An evolving disease. Vet. J. $163: 1-13$

Dosogne, H., F. Vangroenweghe, J. Mehrzad, A. M. Massart-Leen, and C. Burvenich. 2003. Differential leukocyte count method for bovine low somatic cell count milk. J. Dairy Sci. 86:828-834.

DVG. 2002. Leitlinien zur Bekämpfung der Mastitis als Bestandsproblem. DVG (German Veterinary Society), Giessen, Germany.

Hogan, J. S., R. N. Gonzales, R. J. Harmon, S. C. Nickerson, S. P. Oliver, J. W. Pankey, and K. L. Smith. 1999. Laboratory Handbook on Bovine Mastitis. Rev. ed. National Mastitis Council Inc. Madison. WI.

IDF (International Dairy Federation). 2006. Staphylococcus aureus intramammary infections. Bulletin no. 408. IDF, Brussels, Belgium.

Koess, C., and J. Hamann. 2008. Detection of mastitis in the bovine mammary gland by flow cytometry at early stages. J. Dairy Res. $75: 225-232$.

Leitner, G., M. Chaffer, O. Krifucks, A. Glickman, E. Ezra, and A. Saran. 2000a. Milk leucocyte populations in heifers free of udder infection. J. Vet. Med. B Infect. Dis. Vet. Public Health 47:133138.

Leitner, G., R. Eligulashvily, O. Krifucks, S. Perl, and A. Saran. 2003. Immune cell differentiation in mammary gland tissues and milk of cows chronically infected with Staphylococcus aureus. J. Vet. Med. B Infect. Dis. Vet. Public Health 50:45-52.

Leitner, G., E. Shoshani, O. Krifucks, M. Chaffer, and A. Saran. 2000b. Milk leucocyte populations patterns in bovine udder infection of different aetiology. J. Vet. Med. B Infect. Dis. Vet. Public Health 47:581-589.

Lindmark-Mansson, H., C. Branning, G. Alden, and M. Paulsson. 2006. Relationship between somatic cell count, individual leucocyte populations and milk components in bovine udder quarter milk. Int. Dairy J. 16:717-727.

Oliver, S. P., J. S. Hogan, B. M. Jayarao, and W. E. Owens. 2004. Microbiological Procedures for the Diagnosis of Bovine Udder Infection and Determination of Milk Quality. 4th ed. National Mastitis Council Inc., Verona, WI.

Paape, M. J., W. P. Wergin, A. J. Guidry, and R. E. Pearson. 1979. Leukocytes - Second line of defense against invading mastitis pathogens. J. Dairy Sci. 62:135-153.
Park, Y. H., L. K. Fox, M. J. Hamilton, and W. C. Davis. 1992. Bovine mononuclear leukocyte subpopulations in peripheral blood and mammary gland secretions during lactation. J. Dairy Sci. 75:998-1006.

Pilla, R., D. Schwarz, S. König, and R. Piccinini. 2012. Microscopic differential cell counting to identify inflammatory reactions in dairy cow quarter milk samples. J. Dairy Sci. 95:4410-4420.

Riollet, C., P. Rainard, and B. Poutrel. 2001. Cell subpopulations and cytokine expression in cow milk in response to chronic Staphylococcus aureus infection. J. Dairy Sci. 84:1077-1084.

Rivas, A. L., F. W. Quimby, J. Blue, and O. Coksaygan. 2001. Longitudinal evaluation of bovine mammary gland health status by somatic cell counting, flow cytometry, and cytology. J. Vet. Diagn. Invest. 13:399-407.

Schwarz, D., U. S. Diesterbeck, K. Failing, S. Koenig, K. Bruegemann, M. Zschoeck, W. Wolter, and C.-P. Czerny. 2010. Somatic cell counts and bacteriological status in quarter foremilk samples of cows in Hesse, Germany-A longitudinal study. J. Dairy Sci. 93:5716-5728

Schwarz, D., U. S. Diesterbeck, S. Koenig, K. Bruegemann, K. Schlez, M. Zschoeck, W. Wolter, and C.-P. Czerny. 2011a. Microscopic differential cell counts in milk for the evaluation of inflammatory reactions in clinically healthy and subclinically infected bovine mammary glands. J. Dairy Res. 78:448-455.

Schwarz, D., U. S. Diesterbeck, S. Koenig, K. Bruegemann, K. Schlez, M. Zschoeck, W. Wolter, and C.-P. Czerny. 2011b. Flow cytometric differential cell counts in milk for the evaluation of inflammatory reactions in clinically healthy and subclinically infected bovine mammary glands. J. Dairy Sci. 94:5033-5044.

Sordillo, L. M., and S. C. Nickerson. 1988. Morphometric changes in the bovine mammary gland during involution and lactogenesis. Am. J. Vet. Res. 49:1112-1120.

Sordillo, L. M., and K. L. Streicher. 2002. Mammary gland immunity and mastitis susceptibility. J. Mammary Gland Biol. Neoplasia $7: 135-146$

Vangroenweghe, F., H. Dosogne, and C. Burvenich. 2002. Composition and milk cell characteristics in quarter milk fractions of dairy cows with low cell count. Vet. J. 164:254-260.

Zecconi, A., G. Vicenzoni, G. Spreafico, R. Piccinini, and G. Ruffo. 1994. Could teat swabs improve Staph aureus detection? National Mastitis Council Annual Meeting Proceedings, 31.1:366-367. National Mastitis Council, Madison, WI 